\title{
Effect of Doxycycline on Proteinuria in Diabetic Nephropathy
}

Dr. Sushanta Kumar Barman ${ }^{1 *}$, Dr. Md. Nizamuddin chowdhury², Dr. Mohammad Ehasun Uddin Khan ${ }^{3}$, Dr. A.S.M Tanim Anwar ${ }^{4}$, Dr. Monika Roy ${ }^{5}$, Dr Muhammad Anamul Hoque ${ }^{6}$, Dr. Md. Ruhul Amin ${ }^{7}$

${ }^{1}$ Medical Officer, Department of Nephrology, Rangpur Medical College Hospital, Rangpur, Bangladesh

${ }^{2}$ Professor and Head, Department of Nephrology, Dhaka Medical College, Dhaka, Bangladesh

${ }^{3}$ Assistant Professor, Department of Nephrology, Dhaka Medical College, Dhaka, Bangladesh

${ }^{4}$ Assistant Professor, Department of Nephrology Dhaka Medical College, Dhaka, Bangladesh

${ }^{5}$ Lecturer, Dental Pharmacology, Rangpur Medical College Hospital, Rangpur, Bangladesh

${ }^{6}$ Registrar, Department of Medicine, Shaheed Syed Nazrul Islam Medical College Hospital, Kishoregonj, Bangladesh

${ }^{7}$ Registrar, Department of Neurology, Rangpur Medical College Hospital, Rangpur, Bangladesh

DOI: $10.36347 /$ sjams.2020.v08i10.003

| Received: 19.09.2020 | Accepted: 26.09.2020 | Published: 06.10.2020

*Corresponding author: Dr. Sushanta Kumar Barman

Abstract

Original Research Article

Objective: In this study our main goal is to assess antiproteinuric effects of Doxycycline in patients with diabetic nephropathy. Method: This is a prospective interventional study and conducted at the Department of Nephrology in DMCH.The study included 60 clinically proven adult patients of DN. All patients were on optimal doses of angiotensin-converting enzyme inhibitors (ACEIs) or angiotensin receptor blockers (ARBs) for 2 months before the study. The patients were divided into two groups named control (group I, $n=30$ ) and intervention group (group II, $\mathrm{n}=$ 30). Control group patients were maintained on optimal doses of ACEIs or ARBs, whereas intervention group patients received Doxycycline (100 mg/day) for a period of 3 months in addition to ACEIs or ARBs. Data were collected at month 0 and at month 1 at month 3. Results: The study result revealed that before intervention, the mean basal levels of 24 hours proteinuria was $2.2 \pm 1.3 \mathrm{~g}$ /day for Group I and $2.7 \pm 1.42 \mathrm{~g} /$ day for Group II. P value is not significant in both group at baseline $(\mathrm{p}=0.2)$. Adequate glycemic control was achieved with insulin, oral hypoglycemic agents or both in all the patients. It reduced to $2.0 \pm 1.2 \mathrm{~g} /$ day for Group I and $2.5 \pm 1.3 \mathrm{~g} / \mathrm{day}$ for Group II, at the end of $1 \mathrm{month}$. At the end of 3 months, a significant decline of proteinuria was observed in both the groups. In Group I it had a mean of $1.95 \pm 1.2 \mathrm{~g} / \mathrm{day}$, whereas it was $1.25 \pm 0.78 \mathrm{~g} /$ day in Group II. A statistically significant difference existed between the control and intervention groups $(\mathrm{p}<0.05)$, at 3 months. Conclusion: Doxycycline has significantly reduces proteinuria in diabetic nephropathy patients.

Keywords: Doxycycline, nephropathy, proteinuria, albuminuria.

Copyright @ 2020: This is an open-access article distributed under the terms of the Creative Commons Attribution license which permits unrestricted use, distribution, and reproduction in any medium for non-commercial use (NonCommercial, or CC-BY-NC) provided the original author and source are credited.

\section{INTRODUCTION}

Diabetic nephropathy (DN), is one of the leading causes of ESRD worldwide. The risk of nephropathy is strongly determined by polygenetic factors. The risk for development of $\mathrm{DN}$ is equal in type 1 and type 2 diabetes, and $30 \%$ to $40 \%$ of patients with type 1 or type 2 diabetes ultimately develop nephropathy $[1,2,3]$.

It is defined by increased urinary albumin excretion in the absence of other renal diseases [2]. Diabetic nephropathy has been classically defined by the presence of proteinuria $>0.3 \mathrm{~g} / 24 \mathrm{~h}$ [3]. Proteinuria increases mortality and morbidity rate in these patients [4].
Every $50 \%$ decrease in proteinuria during the first 6 months of losartan or placebo treatment was associated with a $36 \%$ reduction in risk for the composite renal end point, a $45 \%$ reduction in risk for ESRD, and an $18 \%$ reduction in risk for CV events during subsequent follow-up [5].

Recent epidemiological research revealed that dyslipidemia also is a risk factor for development and progression of diabetic nephropathy. In addition, dyslipidemia may be a consequence of albuminuria and renal dysfunction, thereby perpetuating kidney damage [6].

DN poses a huge economic burden for developing countries, such as Bangladesh. The Diab Care study in Bangladesh showed that the prevalence of DN among diabetes patients was $8.6 \%$ in an urban 
hospital, and a recent study showed a prevalence of 6.4\% in Rajshahi [7]. Currently ACEI and ARB are the most commonly used drug for reduction of proteinuria. But still research is going on to find out optimum antiproteinuric treatment.

Doxycycline is a potent, broad-spectrum, nonselective MMP inhibitor, acting on both mammalian collagenases and gelatinase and inhibiting the synthesis of MMPs in vivo. Doxycycline can reduce the steadystate level of mRNA for several MMPs. Doxycycline may inhibit collagen gel remodeling by preventing the release or activation of growth factors sequestered in the ECM [8].

The remodeling and excess deposition of ECM could be attenuated by Doxycycline due to its property of MMP inhibition [9].

The role of Doxycycline in decreasing proteinuria in patients with $\mathrm{DN}$ is still largely experimental. Only a few human studies have shown preliminary short-term results. The present study therefore tries to find out if Doxycycline has got any role in decreasing proteinuria in patients with DN.

\section{OBJECTIVE}

\section{General objective}

- To assess antiproteinuric effect of Doxycycline in Diabetic Nephropathy patients.

\section{Specific objective}

- To assess the level of 24 hours proteinuria in control group and intervention group at baseline, at end of $1^{\text {st }}$ month and at the end of $3^{\text {rd }}$ month

- Comparative analysis of proteinuria in both intervention and control group after administration of doxycycline.

\section{Methodology}

\section{Study type}

This study was a Prospective study.

\section{Study place and period}

This study was done at department of Nephrology, Dhaka Medical College Hospital, Dhaka, Bangladesh

\section{Study period}

This study was conducted for a period of one and half years started from January 2017 to july 2018.

\section{Sampling method \\ Non-probability purposive sampling method} was used to select sample population.

\section{Study population \\ Patients of Type 2 DM with clinically proven diabetic nephropathy attending in Nephrology department in DMCH}

Ethical issue: Institutional review board approval and ethical committee clearance has been taken.

\section{Inclusion criteria}

- Adult patients (>18 years) with type $2 \mathrm{DM}$

- Patients with overt proteinuria (>500 mg/24 hr)

- All patients had to be optimal doses of ACEIs or ARBs for at least 2 months before enrollment.

\section{Exclusion criteria}

- History of hypersensitivity to tetracycline derivatives like doxycycline, minocycline.

- Hepatic dysfunction (transaminase levels greater than twice the upper limit of normal

- Uncontrolled Hypertension (blood pressure > 150/90 mm Hg)

- Poorly controlled diabetes

- $\mathrm{eGFR}<15 \mathrm{ml} / \mathrm{min} / 1.73 \mathrm{~m} 2$ (MDRD)

\section{Procedure of data collection:}

A questionnaire was prepared considering key variables like demographic data, clinical presentation, clinical findings, predisposing factors, investigations, were collected which was verified by the guide and the data were collected by the researcher himself. Every patient was gone through detailed history taking and physical examination- special attention to any $\mathrm{H} / \mathrm{O}$ drug allergy. Patient's blood and urine were collected for laboratory analysis.

Patients were purposively selected into a control group and an intervention group. Intervention group patients were received Doxycycline (100 mg daily orally) for 3 months. Patients of the control group were receiving their routine medications. The dosage of anti-hypertensive, anti-diabetic agents, lipid lowering agents, and antiplatelet drugs were continued and adjusted according to the individual patient's clinical condition.

The entire intervention group patient was clinically assessed at $1^{\text {st }}$ month of starting Doxycycline for adverse effect of Doxycycline. Both intervention group and control group patient were assessed clinically and biochemically at 1 and 3 months of treatment. Clinical and biochemical findings of control group and intervention group were compared with each other. All patients who took doxycycline developed no major side-effect during study period. After 3 months doxycycline stopped and conventional treatment were continued. 


\section{Statistical AnAlysis}

After collecting the data, it was checked and rechecked for omission, inconsistencies and improbabilities. After cleaning the data it was edited, coded and entered into the computer. Statistical analysis of the study was be done by computer software device as the Statistical Package for Social Science (SPSS) version 20 (SPSS Inc., Chicago, Illinois, USA).
Continuous variables were expressed as means \pm standard deviation, and categorical variables as frequencies and proportions. The differences between groups were analyzed by independent sample t-test, paired t-test, Wilcoxon Signed Ranktest when necessary. Statistical significance will be assumed when the probability value were less than 0.05

\section{RESULTS}

Table-I: Some baseline parameters in group I and group II

\begin{tabular}{|c|c|c|c|}
\hline & Group I $(n=30)$ & Group II $(n=30)$ & p- value \\
\hline $\begin{array}{l}\text { Age (years) } \\
\text { Mean } \pm\end{array}$ & SD55.6 \pm 10 & $54.7 \pm 9.5$ & 0.94 \\
\hline $\begin{array}{l}\text { Gender } \\
\text { Male } \\
\text { Female }\end{array}$ & $\begin{array}{l}18(56.7 \%) \\
12(53.3 \%)\end{array}$ & $\begin{array}{l}16(53.3 \%) \\
14(46.7 \%)\end{array}$ & 0.36 \\
\hline BMI $*\left(\mathrm{~kg} / \mathrm{m}^{2}\right)$ & $23.86 \pm 2.44$ & $23.81 \pm 2.95$ & 0.08 \\
\hline $\begin{array}{l}\text { Duration of DM*** } \\
<10 \text { years } \\
>10 \text { years }\end{array}$ & $\begin{array}{l}9(30 \%) \\
21(70 \%)\end{array}$ & $\begin{array}{l}12(40 \%) \\
18(60 \%)\end{array}$ & 0.13 \\
\hline
\end{tabular}

BMI*: Body mass index; DM**: Diabetes mellitus

\section{Independent samples to test was used}

Table I shows Mean age of control group and intervention group were $55.60 \pm 10$ and $54.7 \pm 9.5$ respectively, this difference was not statistically significant. No significant difference of BMI in both groups. Male was more than female but difference was not statistically significant. Most patients have duration of DM more than 10 years.

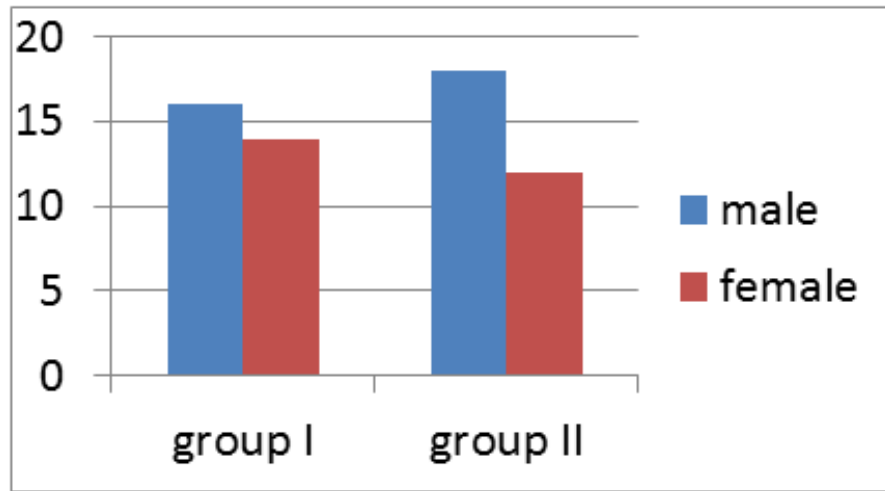

Fig-I: Bar diagram showing distribution of patients according to gender (Group I = 30 and group II = 30) Total 34 male $(56.7$ $\%$ ) and 26 female $(43.3 \%)$ were enrolled in this study. Out of 30 patients in group I 18 were male (56.7\%) and 12 patients were female $(43.3 \%)$ and out of 30 patients in group II 16 patients were male $(53.3 \%)$ and 14 patients were female $(46.7 \%)$.

Table-II: Some baseline parameter of both group I and group II

\begin{tabular}{|l|l|l|}
\hline Baseline parameter & group I & group II \\
\hline ACEI* & $11(27 \%)$ & $9(30 \%)$ \\
\hline ARB** & $19(63 \%)$ & $21(70 \%)$ \\
\hline Hypertension & $30(100 \%)$ & $30(100 \%)$ \\
\hline OHA $\wedge$ & $8(27 \%)$ & $9(30 \%)$ \\
\hline Insulin & $12(40 \%)$ & $12(40 \%)$ \\
\hline Both (OHA, insulin) & $10(33 \%)$ & $9(30 \%)$ \\
\hline
\end{tabular}

ACEI*: angiotensin-converting enzyme inhibitor, $\mathbf{A R B}^{* *}$ : angiotensin receptorblocker $\mathbf{O H A}^{\wedge}$ : oralhypoglycemic drug 
This table shows, group I and group II receiving ACEI 11(27\%), 9(30\%) and ARB 19(63\%), $21(70 \%)$ respectively. Hypertension is equal in both groups. Among anti-diabetic drug insulin was most commonly using drug in both groups.

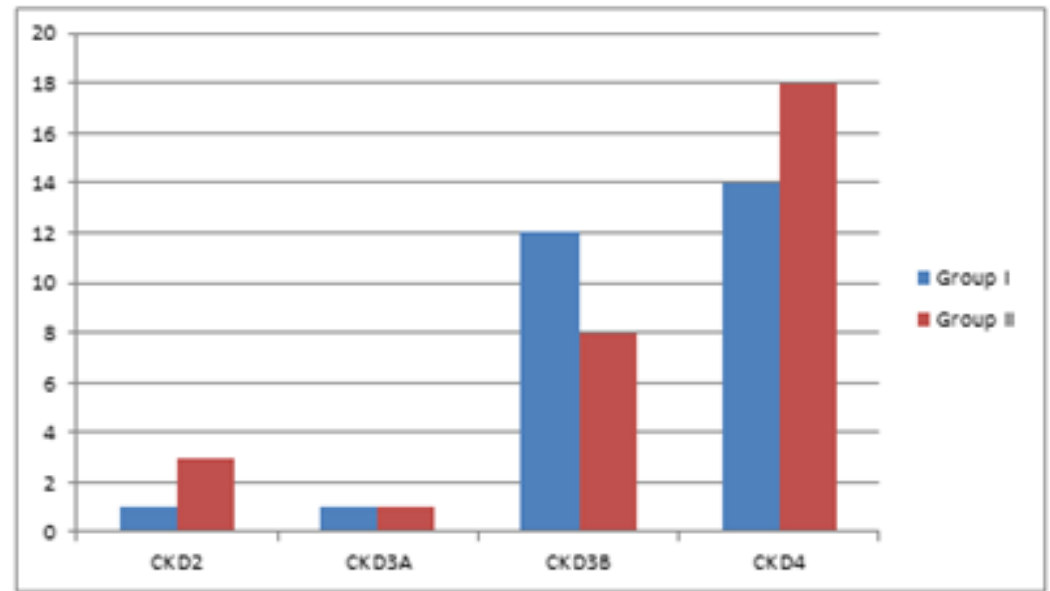

Fig-II: Bar diagram showing distribution of patients according to stages of CKD $($ Group I = 30 and Group II = 30)

Among distribution of CKD patients control group I CKD stage 2 was $1(3.3 \%)$, CKD stage $3 \mathrm{~A}$ $1(3.3 \%)$, CKD stage 3B 12(40\%), CKD stage 4 $14(46.7 \%)$, intervention group II CKD stage 2 was
$3(10 \%)$, CKD stage $3 \mathrm{~A} 1(3.3 \%)$, CKD stage $3 \mathrm{~B}$ $8(26.6 \%)$, CKD stage $418(60 \%)$. Both groups were similar in distribution.

Table-III: Comparison of baseline clinical parameter of between group I and group II

\begin{tabular}{|l|l|l|l|}
\hline Clinical parameter & group I & group II & p-value \\
\hline SBP* (mm Hg) & $131 \pm 6.6$ & $131 \pm 7.7$ & 0.4 \\
\hline DBP** (mm Hg) & $78 \pm 4.7$ & $79 \pm 7.2$ & 0.9 \\
\hline
\end{tabular}

\section{Retinopathy}

$\mathrm{NPDR}^{\wedge} 6(20 \%) 7(23.3 \%)$

$\mathrm{PDR} \wedge \wedge 18(60 \%) 16(53.3 \%)$

Table III shows baseline systolic and diastolic blood pressure in both groups. systolic blood pressure in group I and group II is $131 \pm 6.6$ and $131 \pm 7.7 \mathrm{~mm} \mathrm{Hg}$ respectively and diastolic blood pressure in group I and group II is $78 \pm 4.7$ and $79 \pm 7.2 \mathrm{~mm} \mathrm{Hg}$ respectively and is there was no significant difference in both groups. Majority patients has retinopathy in both groups.

Table-IV: Comparison of baseline biochemical parameters in both group I and group II

\begin{tabular}{|c|c|c|c|}
\hline & $\begin{array}{l}\text { Group I } \\
(\mathbf{n}=\mathbf{3 0})\end{array}$ & $\begin{array}{l}\text { Group II } \\
(\mathbf{n}=\mathbf{3 0})\end{array}$ & \\
\hline $\begin{array}{l}\text { Biochemical } \\
\text { Parameter }\end{array}$ & Mean \pm SD & Mean \pm SD & p- value \\
\hline FBS* (mmol/l) & $6.9 \pm 0.6$ & $6.8 \pm 0.6$ & 0.8 \\
\hline $2 \mathrm{HABF}^{* *}(\mathrm{mmol} / \mathrm{l})$ & $8.3 \pm 0.6$ & $8.2 \pm 0.7$ & 0.2 \\
\hline $\mathbf{H b A 1 C}^{\wedge}(\%)$ & $6.9 \pm 0.6$ & $7.0 \pm 0.6$ & 0.6 \\
\hline Creatinine (mg/dl) & $\begin{array}{l}2 \pm 0.7 \\
0.9\end{array}$ & $2.4 \pm$ & 0.14 \\
\hline e-GFR $(\mathrm{ml} / \mathrm{min})$ & $\begin{array}{l}33 \pm 18.5 \\
19.8\end{array}$ & $31 \pm$ & 0.54 \\
\hline
\end{tabular}

FBS*: fasting blood sugar $\mathbf{2 H A B F}^{* *}$ : 2hours after breakfast

HbA1C $^{\wedge}$ : glycated hemoglobin

\section{Independent sample $t$ test was used}

Table IV showsthe mean values of fasting blood sugar, 2hours after blood sugar, HbA1C, serum creatinine e-GFR between control group (I) and intervention group (II). There was no significant difference between both groups. 
Table-V: Comparison of systolic blood pressure of Groups I and Group II baseline, at end of $1^{\text {st }}$ month, at end of $3^{\text {rd }}$ month

\begin{tabular}{|l|l|l|l|}
\hline $\begin{array}{l}\text { Systolic Blood pressure } \\
\text { (mm of Hg) }\end{array}$ & Group I & Group II & p-value \\
\hline Baseline & $131 \pm 6.6$ & $131 \pm 7.7$ & 0.6 \\
At 1 st $^{\text {month }}$ & $133 \pm 6$ & $133 \pm 7.6$ & 0.7 \\
At 3 month $^{\text {rd }}$ & $130 \pm 7$ & $130 \pm 9.6$ & 0.6 \\
\hline
\end{tabular}

Independent sample $t$ test was used

Table V shows systolic blood pressure among both groups. Systolic blood pressure at baseline, at the end of first month, at the end of third month in group I is $131 \pm 6.6,133 \pm 6,130 \pm 7 \mathrm{~mm} \mathrm{Hg}$ and group II $131 \pm$
7.7, $133 \pm 7.6,130 \pm 9.6 \mathrm{~mm} \mathrm{Hg}$ respectively .No significant change was noted in systolic BP in baseline, at the end of first month, at the end of third month in between both groups.

Table-VI: Comparison of diastolic blood pressure of Groups I and Group II baseline, at end of $1^{\text {st }}$ month, at end of $3^{\text {rd }}$ month

\begin{tabular}{|c|c|c|c|}
\hline $\begin{array}{c}\text { Diastolic Blood pressure } \\
(\mathrm{mm} \text { of } \mathbf{H g})\end{array}$ & Group I & Group II & p-value \\
\hline $\begin{array}{l}\text { Baseline } \\
\text { At } 1^{\text {st }} \text { month } \\
\text { At } 3^{\text {rd }} \text { month }\end{array}$ & $\begin{array}{l}78 \pm 4.7 \\
79 \pm 6 \\
80 \pm 4.2\end{array}$ & $\begin{array}{l}79 \pm 7.2 \\
83 \pm 5.8 \\
80 \pm 6.6\end{array}$ & $\begin{array}{l}0.9 \\
0.64 \\
0.37\end{array}$ \\
\hline
\end{tabular}

Independent sample t test was used

Table VI shows diastolic blood pressure among both groups. Diastolic blood pressure at baseline, at the end of first month, at the end of third month in group I is $78 \pm 4.7,79 \pm 680 \pm 4.2 \mathrm{~mm} \mathrm{Hg}$ and group II $79 \pm 7.2,83 \pm 5.8,80 \pm 6.6 \mathrm{~mm} \mathrm{Hg}$ respectively. No significant changes in diastolic blood pressure at baseline, at the end of first month, at the end of third month between both groups.

\section{DISCUSSION}

Newer treatment options are continuously on research. Doxycycline is a promising drug used for another indication. But based on its pharmacodynamics and pharmacokinetics it was hypothesized that it may have effect on proteinuria. Therefore, a prospective interventional study was designed to see the effects of doxycycline on proteinuria in diabetic patients with diabetic nephropathy. Total 60 clinically proven diabetic nephropathy patients were enrolled in this study. 30 patients were grouped as control (Group I) and had on usual treatment protocol. Another 30 patients who had received conventional antiproteinuric treatment with doxycycline for 3 months of period were considered in the intervention group (Group II). Baseline investigation were done in two group to determine the outcome of intervention (100mg doxycycline per day for 3 months orally). Male patients are in increased risk of developing nephropathy in diabetes showed in many studies. Gall et al. found that males had a 2.6 times greater risk of developing incipient or overt nephropathy [10]. In our study, it was similar, as male was more than female $(56.7 \%$ vs 43.3 $\%$ ). And this finding is also supported by by Aaberg et al. [11]. Certain base line physical characteristics (SBP, DBP) were collected before intervention. Mean systolic blood pressure of control and intervention group were
$131 \pm 6.6$ and $131 \pm 7.7$ respectively; mean diastolic blood pressure were $78 \pm 4.7$ and $79 \pm 7.2$ respectively. These parameters taken at the end of first month and at the end of third month but there was no significant difference between control and intervention groups ( $\mathrm{p}$ $>0.05$ ). This finding is consistent with similar study by Hari krishan and Deepak Jain [13].

Moreover, the effect ofstudy participants were also assessed serum creatinine and e-GFR between control group (I) and intervention group (II) before starting intervention (Doxycycline). There is no significant difference were noted in distribution of serum creatinine $(p=0.14)$, e-GFR across groups $(p$ value $=0.54)$. Observation evidenced that there is no significant change was noted in Creatinine and e-GFR values of both group I and II, when month 0 values were compared with month 3 values after giving intervention. Those findings are supported by the study Hari Krishan et al., [13]. From this it was assumed that doxycycline has no effect (beneficial/deleterious) on these renal parameters.

The study was focused on to see the effect of Doxycycline on proteinuria. Mean pre-intervention 24 hours proteinuria in $2.2 \pm 1.3 \mathrm{~g} /$ day (range $0.63-5.0$ $\mathrm{g} /$ day) for Group I and $2.7 \pm 1.42 \mathrm{~g} /$ day (range $0.51-$ $5.0 \mathrm{~g} /$ day) for Group II. Difference in distribution of 24 hours proteinuria between two groups (pre intervention) was not significant ( $p$ value 0.2). But following intervention of Doxycycline (oral $100 \mathrm{mg}$ once daily for 3 month) and observation of this two group (intervention and control) at month zero and month 3 showed, a significant change in 24 hours proteinuria at month 3 in group II (intervention group) ( $\mathrm{p}$ value $=$ 0.01 ). The findings are similar to the study done by Hari Krishan et al., [13] and showed significant reduction of 
proteinuria in intervention group than control group ( $\mathrm{p}$ $<0.05)$. Similar finding was also supported by Naini $e t$ al. [9].

The delayed response seen after 3 months and not immediately after 1 month may be due to altered expression of MMPs and degradation of ECM proteins in the presence of the drug [13].

The antiproteinuric effect of doxycycline was achieved with a good compliance and no apparent serious adverse effect.

\section{Conclusion}

In this study, Doxycycline has shown to reduction of proteinuria patients, on traditional antiproteinuric drug in diabetic nephropathy.

\section{REFERENCES}

1. Wolf G, Sharma K. Pathogenesis, Clinical Manifestations, and Natural History of Diabetic Nephropathy. In: Johnson RJ, Feehally J, Jurgen Floege. Comprehensive Clinical Nephrology: $15^{\text {th }}$ ed. Elsevier; 2015.

2. Gross JL, De Azevedo MJ, Silveiro SP, Canani LH, Caramori ML, Zelmanovitz T. Diabetic nephropathy: diagnosis, prevention, and treatment. Diabetes care. 2005 Jan 1;28(1):164-76.

3. Mogensen CE, Christensen CK. Predicting diabetic nephropathy in insulin-dependent patients. New England Journal of Medicine. 1984 Jul 12;311(2):89-93.

4. Valmadrid CT, Klein R, Moss SE, Klein BE. The risk of cardiovascular disease mortality associated with microalbuminuria and gross proteinuria in persons with older-onset diabetes mellitus. Archives of internal medicine. 2000 Apr 24;160(8):1093-100.

5. De Zeeuw D, Remuzzi G, Parving HH, Keane WF, Zhang Z, Shahinfar S, Snapinn S, Cooper ME,
Mitch WE, Brenner BM. Proteinuria, a target for renoprotection in patients with type 2 diabetic nephropathy: lessons from RENAAL. Kidney international. 2004 Jun 1;65(6):2309-20.

6. Toyama T, Shimizu M, Furuichi K. Clin Exp Nephrol. 2014; 18: 201.

7. Islam SM, Alam DS, Wahiduzzaman M, Niessen LW, Froeschl G, Ferrari U, Seissler J, Rouf HM, Lechner A. Clinical characteristics and complications of patients with type 2 diabetes attending an urban hospital in Bangladesh. Diabetes \& Metabolic Syndrome: Clinical Research \& Reviews. 2015 Jan 1;9(1):7-13.

8. Franco C, Ho B, Mulholland D, Hou G, Islam M, Donaldson K, Bendeck MP. Doxycycline alters vascular smooth muscle cell adhesion, migration, and reorganization of fibrillar collagen matrices. The American journal of pathology. 2006 May 1;168(5):1697-709.

9. Naini AE, Harandi AA, Moghtaderi J, Bastani B, Amiran A. Doxycycline: a pilot study to reduce diabetic proteinuria. American journal of nephrology. 2007;27(3):269-73.

10. Gall MA, Hougaard P, Borch-Johnsen K, Parving HH. Risk factors for development of incipient and overt diabetic nephropathy in patients with noninsulin dependent diabetes mellitus: prospective, observational study. Bmj. 1997 Mar 15;314(7083):783.

11. Aaberg ML, Burch DM, Hud ZR, Zacharias MP. Gender differences in the onset of diabetic neuropathy. Journal of Diabetes and its Complications. 2008 Mar 1;22(2):83-7.

12. Gross JL, De Azevedo MJ, Silveiro SP, Canani LH, Caramori ML, Zelmanovitz T. Diabetic nephropathy: diagnosis, prevention, and treatment. Diabetes care. 2005 Jan 1;28(1):164-76.

13. Hari Krishan Aggarwal, Deepak Jain. Evaluation of role of doxycyclin on renal functions in patients of diabetic nephropathy. Renal Failure. 2010; 32: 941-946. 